One of the youngest of the voluntary national health agencies, United Cerebral Palsy, is making a fight against the crippling condition that affects more than half a million people in the United States today.

\title{
United Cerebral Palsy
}

\author{
-Its Growth and Present Status-
}

\section{By GLIDDEN L. BROOKS, M.D., and ISIDORE ALTMAN, Ph.D.}

$C_{1}$ EREBRAL PALSY has been defined by Phelps as "comprising a group of conditions which affect the control of the voluntary motor system and which have their origin in lesions of various parts of the brain" (1). Among the more common clinical signs are lack of balance, awkward posture and gait, uncontrollable movements of the arms or legs, and impaired speech, hearing, and vision. At least half of all cases also suffer some degree of impairment of mental capacity. In addition, disturbances of perception may be present.

The nature and extent of the disability depend on the location and the extent of the damage to the brain. The damage may occur before, during, or after birth, or subsequently as the result of a head injury, encephalitis,

Dr. Brooks has been medical director of United Cerebral Palsy Associations since 1953. Prior to that, he was coordinator of hospital clinics and professor of hospital administration of the Graduate School of Public Health, University of Pittsburgh. Dr. Altman is assistant professor of biostatistics of the Graduate School and statistical consultant of United Cerebral Palsy.

Vol. 70, No. 11, November 1955

$359047-55-5$ poisoning, or other brain-injuring situation. However, the great majority of the cerebral palsied sustain brain injury during the prenatal or paranatal period. Among the likely etiological factors are anoxia, brain hemorrhage, prematurity, blood incompatability (Rh factor), and malformation of the brain.

The precise incidence and prevalence of cerebral palsy remain to be established. Estimates based on the few scattered surveys that have been made indicate that the prevalence rate is approximately 3 to 3.5 cases per 1,000 population and that there are about 570,000 cases in the United States today. The Children's Bureau has estimated that "somewhere in the neighborhood of 285,000 children under 21 in the United States in 1952 have cerebral palsy either from birth or as a result of subsequent brain damage" (2).

Cerebral palsy presents many more kinds of problems than just those of medical care. It presents special problems in the fields of education, psychology, vocational guidance and training, and recreation. Because of the involved relationships between parent and afflicted child, programs are also needed for family education and counseling. An added problem is the provision of transportation and 
its attendant costs, for many of these children could not otherwise be moved to and from their various activities.

\section{The Associations}

United Cerebral Palsy Associations, Inc., came into being in 1949. The reasons for its existence and for the existence of similar organizations have been ably expressed by Courville (3): "A new trend in the attack on disease, one introduced even before the beginning of World War II, is the association of lay and professional groups in an attempt to answer the questions posed by some particular disorder. The lay representatives owe their interest as a rule to the fact that some member of their own family is a victim of the disease in question. The professional groups are those whose special training or interests naturally incline them to its study. It is this common concern for the social as well as the medical effects of a given condition which unites the "two groups in seeking a solution to the problem."

United Cerebral Palsy was founded through the efforts of parents of the cerebral palsied. On April 1, 1954, it had 356 affiliates, with affiliates in all States and the District of Columbia. It has grown, in terms of contributions from the public, from an organization with an initial income in 1950 of $\$ 1,022,000$ to one with an income in 1954 of $\$ 8,242,000$.

\section{Autonomous Affiliates}

The local affiliates are autonomous, raising their own funds and expending these funds as they see fit, except that 25 percent of their income is used for participation in the national program. It is they who assume the responsibility for seeing that services are provided for cerebral palsied persons who live in their communities. State offices have been established in a number of States mainly for the purpose of stimulating and coordinating local activity. These are supported by locally determined percentages of income, generally about 5 percent. The national office promotes the growth of the organization, provides specialists for advice and assistance to local affiliates in the development of services, fund raising, public relations, and legislation, and fosters a research and training program through grants.

The objective of a local affiliate is to make certain that the needs of the cerebral palsied are being met. This means mobilization of community resources through financial support of agencies providing some of the services, seeking legislation for services that government should provide, case finding and evaluation of resources, and the actual establishment and operation of facilities where this is deemed the most effective means of providing services.

\section{A Selected Local}

Because United Cerebral Palsy is still a rapidly growing organization and because size and growth of program vary considerably from community to community, it is difficult to assess the success with which the objective just stated is being achieved. Instead of a nationwide examination, the activities of one of the older affiliates will be described as indicative of the trends in the development of affiliate programs.

The selected local United Cerebral Palsy agency made a total expenditure of $\$ 70,000$, in round figures, for services in the year ending June $30,1954-\$ 24,000$ for medical services, $\$ 35,000$ for education, $\$ 5,000$ for recreation, $\$ 1,000$ for parent education and counseling, and $\$ 5,000$ for transporting cerebral palsied persons to places where they could receive these services.

The medical program to which the affiliate contributed $\$ 24,000$ is administered by a children's hospital connected with an outstanding medical school. Its cerebral palsy unit provides screening for purposes of diagnosis and all the facilities and personnel necessary to speech, occupational, and physical therapy. During the year, 267 patients were served on an outpatient basis; of these, 129 , or 48 percent, were under 5 years of age. It is important to successful prognosis that the child be brought to treatment as early as possible.

The funds for education were devoted largely to the maintenance of a nursery school, with 28 children, in the medical center mentioned above. The $\$ 20,000$ contributed by the affiliate made up a fifth of the nursery school's total budget. Another $\$ 10,000$ went for educational purposes in 
a hospital devoted to the rehabilitation of handicapped children. The remaining $\$ 5,000$ helped to maintain an industrial school for crippled children, which last year had 43 cerebral palsied enrollees.

Recreational activities consist in bringing children to a center one day a week for games, art work, and even dancing. One of the notable achievements of this particular affiliate is the formation of a choral group made up of cerebral palsied adults. Other affiliates contribute to the general support of summer day camps and residential camps or meet the costs for a number of cases.

Parents meet at bimonthly intervals to hear authorities speak on various aspects of cerebral palsy. In addition, individual counseling is provided on social and health development of the child and on such specific problems as feeding, dressing, and exercising. The parents themselves contribute a considerable amount of voluntary services in raising funds, furnishing transportation, taking the children on outings, and the like.

While this local organization incurred no expenditures for services of a vocational nature, cerebral palsied adults have been placed in employment or for training through consultation with rehabilitation agencies and workshops in the community. A number of affiliates of United Cerebral Palsy maintain sheltered workshops where training and jobs are provided to fit the capacities of the handicapped individual, while other affiliates provide counseling or offer vocational services.

Thus, the affiliates of United Cerebral Palsy make a contribution to public health progress through the active support of diagnostic and treatment centers and other services to alleviate a handicapping condition which is costly to the community, both economically and socially. They make a further contribution through support of a research program which seeks to find the causes of cerebral palsy and thereby to prevent it.

\section{The National Office}

The function of promoting research and the training of professional personnel, on the whole, is vested in the national office. The method followed in making research grants is patterned for the most part after the system developed by the National Institutes of Health. Applicants for grants must have a university affiliation or be connected with some other responsible and recognized institution to which the money is actually paid. Applications are received and rated by a research advisory board made up of distinguished neurologists, surgeons, pediatricians, and specialists in other fields related to cerebral palsy. A medical executive board reviews the recommendations of this and other advisory boards and makes final recommendations to the lay governing body. Up to September 30, 1954, United Cerebral Palsy has spent almost $\$ 1,400,000$ for its research and training program.

To date, the emphasis of this program has been mainly on basic neurological research, oriented toward the goal of prevention. The number of grants made for research into problems of education, social development and adjustment, and mental status is expected to increase. Research projects currently under way fall into five broad groups of studies:

1. The physical structure of the normal and damaged brain.

2. The chemical structure of the normal and damaged brain.

3. The function of the normal and damaged brain.

4. Causes of brain damage.

5. The nature and characteristics of the cerebral palsied.

The training program consists of $(a)$ direct grants to the American Physical Therapy Association and the American Occupational Therapy Association for training recruits in their respective fields; (b) summer workshops for teachers and therapists at eight colleges and universities; (c) fellowships for dentists and dental hygienists; $(d)$ support of postgraduate courses for therapists; and (e) miscellaneous training programs.

The program division of the national office, which is charged with developing principles of program services and with general supervision of the research and training grants, carries on active liaison with other national agencies in such related fields as public health, education, and rehabilitation. It is represented on com- 
mittees and boards of the National Health Council, American Public Health Association, International Council for Retarded Children, American Occupational Therapy Association, and other similar organizations. United Cerebral Palsy recognizes full well that it will take the concerted efforts of many national agencies, in cooperation with government, to conquer the disorder in which it is particularly interested.

\section{One of a Group}

United Cerebral Palsy is now one of a group of prominent voluntary national health agencies which perform an important function in public health. By concentrating on a single disorder or group of disorders, these associations can provide or support a high level of service and bend special efforts toward ultimate eradication. In the community, they bring together a devoted group of lay and professional people in a dedicated cause.

As for cerebral palsy specifically, Surgeon General Scheele, in addressing the 1954 convention of United Cerebral Palsy, had this to say : "It is an old public health axiom, proved seventy times seven, that however massive and complex a problem may be, it will eventually be solved by attacking its various elements one by one. The success of the attack depends upon the breaking down of the broad problem into a series of research problems and solving them. This approach is especially valuable in the attack on cerebral palsy ...

"The idea of preventing a large share of the cases of cerebral palsy now occurring each year may seem like a dream. But I believe that it is a distinct possibility. I believe too that medical research is on the threshold of other important discoveries that will greatly improve the status of many victims of cerebral palsy. Only through persistent research effort in the many specific areas of cause and prevention, treatment and rehabilitation can we truly vanquish this enemy that causes so much heartbreak and suffering."

\section{REFERENCES}

(1) Phelps, W. M.: The cerebral palsies. In MitchellNelson textbook of pediatrics. Ed. 4. Philadelphia, W. B. Saunders Co., Philadelphia, 1946, p. 1111.

(2) Lesser, A. J., and Hunt, E. P.: The Nation's handicapped children. Am. J. Pub. Health 44 : 166-170, February 1954.

(ङ) Courville, C. B.: Cerebral palsy. Ios Angeles, San Lucas Press, 1954, p. 1.

\section{Scholarships in Cancer Research}

The National Research Council's Committee on Growth is accepting applications for American Cancer Society grants to assist young scientists during the critical early period of their careers in cancer research.

Awards are made for 3-year periods at $\$ 6,000$ annually with possible renewal for 2 additional years. Applications should be submitted by institutions on behalf of candidates not later than January 1, 1956. - Forms and information may be obtained from the Executive Secretary, Committee on Growth, National Academy of SciencesNational Research Council, 2101 Constitution Avenue, N.W., Washington $25, \mathrm{D}$. C. 